\title{
THE RELIABILITY ASSESSMENT OF THE TLS REGISTRATION METHODS - THE CASE STUDY OF THE ROYAL CASTLE IN WARSAW
}

\author{
Jakub Markiewicz ${ }^{1}$, Sławomir Łapiński ${ }^{1 *}$, Agnieszka Bocheńska², Patryk Kot ${ }^{3}$ \\ 1 Faculty of Geodesy and Cartography, Warsaw University of Technology, Warsaw, Poland - (jakub.markiewicz, slawomir.lapinski)@pw.edu.pl, \\ 2 The Royal Castle in Warsaw, Archaeology Department, Warsaw, Poland - abochenska@ zamek-krolewski.pl, \\ 3 Built Environment and Sustainable Technologies (BEST) Research Institute, Liverpool John Moores University, \\ L3 3AF, Liverpool, United Kingdom - P.Kot@ljmu.ac.uk.
}

Commission II

KEY WORDS: TLS Registration, 3D Network Adjustment, Reliability Analysis, Cultural Heritage, Royal Castle in Warsaw.

\begin{abstract}
:
Modern measurement technologies are commonly applied to monitor and preserve the cultural heritage as it is an integral part of modern societies. The Terrestrial Laser Scanning (TLS) method is one of the common technologies investigated by the researchers for accurate data acquisition and processing required for architectural documentation. In recent years, many methods were developed for TLS data registration to improve the processing time and accuracy of the bundle adjustment. The aim of this research is to compare the existing TLS target-based registration methods and compare them with the proposed novel method based on the reliability assessment- the robustness analysis. The novel feature-based approach also includes $2 \mathrm{D}$ detectors, which were applied to the TLS data converted into spherical images. Measurements were carried out at the Royal Castle in Warsaw using TLS Z+F 5006H and total station Leica TCRP1202. The collected data was analysed using existing software Z+F LaserControl, LupoScan and developed the application to perform $2 \mathrm{D}+1 \mathrm{H} / 3 \mathrm{D}$ registration. The main results demonstrated that the proposed method for TLS registration removed the outliers that could not be eliminated by the deviation analysis on control and check points. The accuracy of TLS registration increased with a RMSE difference between $0.1 \mathrm{~mm}$ and $3.7 \mathrm{~mm}$ in comparison to existing methods. Furthermore, the accuracy of the results from 2D detectors was improved with relative orientation RMSE $\leq 2.1 \mathrm{~mm}$ and equivalent for control and check points for $\mathrm{X}, \mathrm{Y}$, and $\mathrm{Z}$ coordinates in comparison to target-based registration.
\end{abstract}

\section{INTRODUCTION}

Cultural heritage is evidence of the past and became an integral part of modern societies. In order to protect and preserve the cultural heritage object and sites, it is necessary to perform the architectural documentation in the form of 3D point clouds, 3D models, orthoimages and vector drawing (Stylianidis, 2019) for this purpose image and range-based method are used (Abbate et al., 2019; Arif and Essa, 2017; Cipriani et al., 2019; Grussenmeyer and Yasmine, 2004; Hatzopoulos et al., 2017; Heras et al., 2019; Kot et al., 2020; Markiewicz et al., 2020, 2017; Remondino and El-Hakim, 2006). The selection of the appropriate method for 3D documentation generation determines the way of surveying data pre-processing (Tobiasz et al., 2019). The aim of this article is to present the investigation of the quality assessment for different TLS registration methods. In this article, the comparison of the existing targetbased registration (implemented in the $\mathrm{Z}+\mathrm{F}$ LaserControl and LupoScan software) with the proposed novel method based on the reliability assessment (target and feature-based) were performed.

\section{STATE OF THE ART}

\subsection{The TLS registration methods overview}

The first and one of the most important steps in the TLS data processing pipeline is the registration step. It involves the transformation of the point cloud in the assumed reference system, which may be the stated coordinate system, a local system, or an internal system related to the master scan (Cheng ${ }^{*}$ Corresponding author et al., 2018). For large and complex historical objects and sites, it is impossible to obtain only data from one TLS position, and multiple point clouds must be transformed into the assumed reference system. This process relies on the detection of corresponding points, shapes or features in at least two-point clouds, and the exterior orientation parameters are obtained for each scan. These parameters determine the spatial location of the central point of the scanner system in the assumed reference system together with three rotation angles, which are then used to transform the point cloud.

For this purpose, the 3D affine transformation is usually applied. However, if there are significant scale differences between the scanner system and the external reference system, it is recommended to apply the $3 \mathrm{D}$ similarity transformation (Markiewicz and Zawieska, 2019), which is performed on a minimum of three tie points distributed within the entire analysed area. The most common solution for obtaining the coordinates of control and check points, which are determined in an exterior coordinate system, are classic angular and linear measurements performed with a total station (TS) and an independent alignment of observations including horizontal angles and distances in case of a $2 \mathrm{D}$ network and height differences in a 1D network.

When the number of tie points is increased, redundant observations are created; therefore, the accuracy of data registration is also increased. This also allows for the elimination of outliers and perform the reliability assessment based on the covariance matrices approach. The relation between the local instrument system and the global reference system is expressed in Equation 1, also known as rigid-body 
transformation in the least-square method (uncorrelated observations):

$$
\begin{gathered}
\sum_{A x=y+v} v v=\min \\
M_{\text {ext }}=R_{\omega \varphi x} * M_{\text {int }}+T
\end{gathered}
$$

where $v$ - the deviation between the reference and transformed tie point

$A$ - coefficient matrix based on the tie points

$x$ - estimated transformation parameters

$y$ - the difference between coordinates in the reference system and computed by the transformation matrix

$M_{\text {ext }}$ - the vector of the coordinates of points in the global system

$M_{\text {int }}$ - the vector of the coordinates of points in the local (scanner) reference system

$\mathrm{T}$ - translation vector

$\mathrm{R}_{\omega \varphi \kappa}$ - the rotation matrix

Several TLS registration methods exist (Durrant-Whyte and Bailey, 2006; Liu, 2006; Nuchter et al., 2007; Sprickerhof et al., 2009; Theiler and Schindler, 2012; Van Genderen, 2011; Vosselman and Maas, 2010), which can be divided into two groups comprising pairwise and multiview registration, depending on the amount of input point clouds (Deng et al., 2018; Dong et al., 2020).

\subsection{The reliability assessment - the covariance matrix} analysis approach

The theory of reliability is commonly used to diagnose outliers in the surveying data, while this article will explore the use of this method for the determination of outliers in the tie points (used for TLS registration). The proposed approach will compensate the orientation quality based on the local reliability criteria, which enables to determine if the pair of tie points are correctly matched. The proposed method of quality assessment will not only focus on the RMSE on control and check points evaluation, but it will take into account the points spatial distribution.

Based on the least square method (Equation 1), the formula for local reliability criteria is determined (Equation 3), which is called the "disorder-response" dependency and is one of the basic elements of reliability theory (Baarda, 1968; Rofatto et al., 2020). A detailed description of these equations was presented by Prószyński (1994).

$$
\begin{gathered}
\mathbf{v}=-\mathbf{R} \mathbf{y} \\
\mathbf{R}=\mathbf{I}-\mathbf{A}\left(\mathbf{A}^{\mathrm{T}} \mathbf{A}\right)^{-1} \mathbf{A}^{\mathrm{T}}
\end{gathered}
$$

where: $\quad \mathbf{R}-$ reliability matrix of the tie points I - identity matrix A - coefficient matrix based on the tie points
To analyse the internal reliability factors, the diagonal value of the matrix $\mathrm{R}$ must be tested. The matrix $\mathrm{R}$ is an orthogonal projection operator, where the range of values on diagonal are between $\langle 0,1\rangle$. According to the definition of internal reliability, $\{\mathrm{R}\}_{\mathrm{ii}}=0$ when this tie point is completely uncontrolled. However, when $\{R\}_{i i} \cong 1$ - tie point is fully controllable by other tie points. It is stated that the spatial tie points are well distributed in terms of reliability when the internal reliability criteria for each tie point is $\{\mathrm{R}\}_{\mathrm{ii}}>0.5$.

\section{MATERIALS AND METHODS}

\subsection{The test site description - Royal Castle in Warsaw}

The subject of the analysis is the basement rooms located on the lowest floor of the Tin-Roofed Palace (Figure 1), which is now an integral part of the architectural complex of the Royal Castle in Warsaw. This part of the Royal Castle is an original one and wasn't destroyed during the Warsaw Uprising in 1944. The palace adjoined the Castle building from the south and was finally incorporated into it by erecting Royal Library in the years $1779-82$, situated on the northern wing of the palace. The cellars are the part of its main body, on the west side, and belong to the oldest construction phase. These are the remains of the first known building in this area - the house of Wawrzyniec Reffus, the royal armourer.

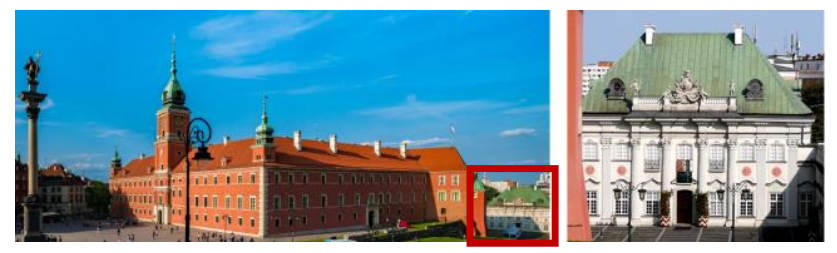

Figure 1. The Royal Castle in Warsaw with Tin-Roofed Palace (Polish Monuments, 2021; Polish Tourism Organisation, 2021)

The history of the tenement house dates to the mid -17 th century when between 1651 and 1655 , a grand patrician house was built on this plot. In the years 2004-2008, the palace underwent a major renovation but without the basement. The restoration of these rooms has been postponed (The Royal Castle in Warsaw, 2021). While preparing for the future renovation works, it was decided to take a non-invasion inventory of the interiors, such as TLS surveying (Figure 2).

\subsection{The method description}

The data acquisition and processing schema was divided into four main parts: (1) Data acquisition and pre-processing, (2) Relative registration - quality assessment, (3) The reliability assessment - the robustness analysis, (4) Exterior registration quality assessment (Figure 3).

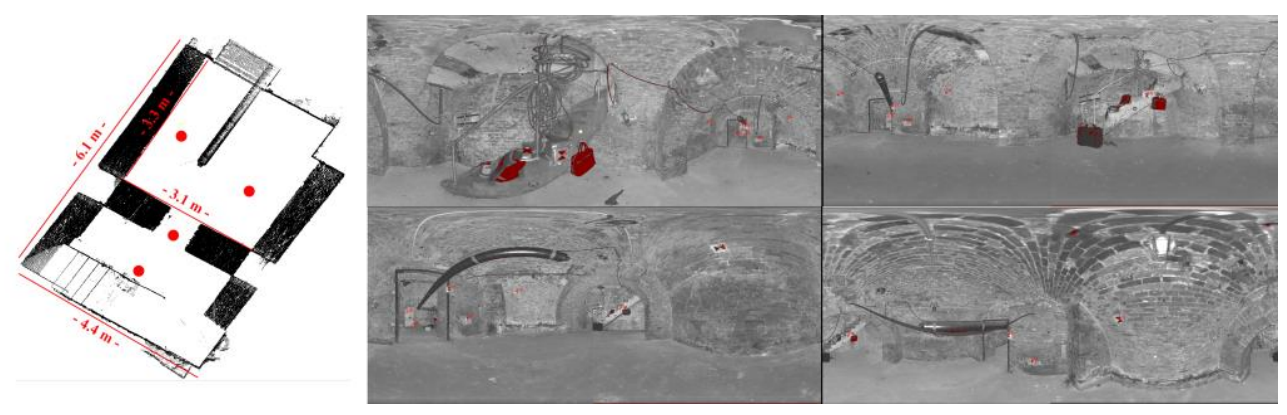

Figure 2. The floor plan with marked Terrestrial Laser Scanning (TLS) scanner positions and four TLS point clouds as spherical images 


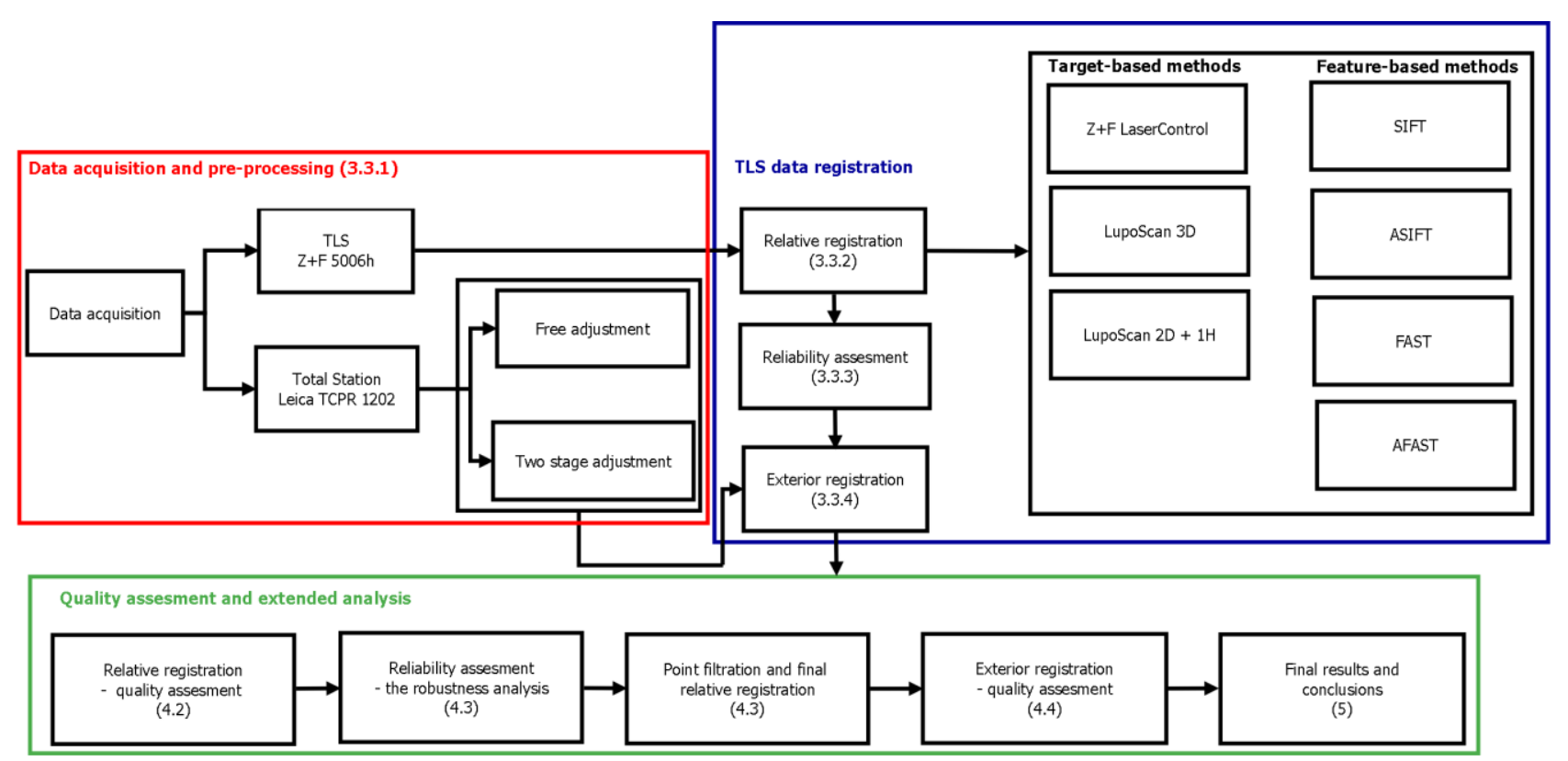

Figure 3. Diagram of the performed experiments: data acquisition, processing and analysis.

\subsection{The method description}

The data acquisition and processing schema was divided into four main parts: (1) Data acquisition and pre-processing, (2) Relative registration - quality assessment, (3) The reliability assessment - the robustness analysis, (4) Exterior registration quality assessment (Figure 3).

\subsubsection{Data acquisition and pre-processing}

The initial data acquisition process was divided into two parts (1) TLS measurement with Z+F 5006h with resolution $6.1 \mathrm{~mm} /$ $10 \mathrm{~m}$ and (2) Total Station measurement with Leica TCRP 1202 with angular accuracy $2 \mathrm{sec}$., linear accuracy $2 \mathrm{~mm}+2 \mathrm{ppm}$.

The TLS data acquired 4-point clouds with angular resolution $360^{\circ} / 320^{\circ}$ at 4 different hight of station position. The total station acquired data from 2 measurement stations and at 2-time series to ensure the accuracy, reliability of the data and removal of errors. The ground control points were used for the TLS checkboard, and retroreflective targets were used for Total Station (TS) to determine the reference system.

In order to validate the reference system, two approaches were used: (1) the free network adjustment of observation for all points in one bundle adjustment and (2) the two-stage adjustment: (a) first order network determination bases on retroreflective targets and (b) network adjustment in reference to first order network.

\subsubsection{Relative registration - quality assessment}

For semi-automatic marked point measurement and registration, the commercial software Z+F Laser Control and LupoScan were used. For fully automatic tie point detection, the featurebased method was used, which contains the following steps: (1) convert TLS data into the spherical image with depth map, (2) detect keypoints with SIFT, ASIFT, FAST and AFAST algorithm, (3) keypoint description (2D SIFT descriptor) and descriptor matching, (4) outliers detection and geometrical verification with relative parameters computation (RANSAC method) and (5) automatic division of detected tie points into the control and check and final registration based on intersection method.

\subsubsection{The reliability assessment - the robustness analysis}

The tie points were examined with regards to accuracy and network reliability. The analysis was performed to assess the methods of data registration to obtain the highest accuracy and robustness (Equation 2 and 3). This step allowed to eliminate outliers and analyse network reliability in the local coordinate system.

\subsubsection{Exterior registration - quality assessment}

For existing target-based and feature-based methods, the control points were assigned to the exterior coordinate reference system from TS measurements.

\section{RESULTS AND DISCUSSIONS}

\subsection{Data acquisition and pre-processing}

The first step of data processing involves total station data preparation and bundle adjustment using two methods 1) free adjustment, 2) two-stage adjustment.

Table 1 demonstrates the results of statistical analysis (minimum, maximum, average, and median) on the deviation analysis on control and check points.

\begin{tabular}{|c|c|c|c|}
\hline \multicolumn{4}{|c|}{ Free adjustment } \\
\hline \multirow{2}{*}{} & \multicolumn{3}{|c|}{ Deviation } \\
\cline { 2 - 4 } & $\mathrm{X}[\mathrm{mm}]$ & $\mathrm{Y}[\mathrm{mm}]$ & $\mathrm{Z}[\mathrm{mm}]$ \\
\hline Min & 1.1 & 0.6 & 0.3 \\
\hline Max & 3.0 & 2.5 & 0.5 \\
\hline Average & 2.2 & 1.3 & 0.4 \\
\hline Median & 2.1 & 1.0 & 0.5 \\
\hline \multicolumn{4}{|c|}{ Two-stage adjustment } \\
\hline \multirow{4}{|c|}{ Deviation } \\
\cline { 2 - 4 } & $\mathrm{X}[\mathrm{mm}]$ & $\mathrm{Y}[\mathrm{mm}]$ & $\mathrm{Z}[\mathrm{mm}]$ \\
\hline Min & 0.4 & 0.2 & 0.3 \\
\hline Max & 3.0 & 2.4 & 0.4 \\
\hline Average & 2.0 & 1.1 & 0.3 \\
\hline Median & 2.0 & 0.8 & 0.4 \\
\hline
\end{tabular}

Table 1. The statistical analysis of the result of the free and two-stage adjustment. 
The results demonstrated that there is no significant difference between both methods. The similarity between Average and Median values indicates that the bundle adjustment process for the two methods was performed correctly without the presence of outliers. It is not necessary to perform twice bundle adjustment process (separately for retroreflective points and TLS reference points), but it can be completed in a single step process (free adjustment).

\subsection{Relative registration - quality assessment}

Figure 4 presents the results of the relative registration on the control points using $\mathrm{Z}+\mathrm{F}$, LupoScan 3D, LupoScan $2 \mathrm{D}+1 \mathrm{H}$ (existing methods), SIFT, ASIFT, FAST and AFAST (novel proposed methods).

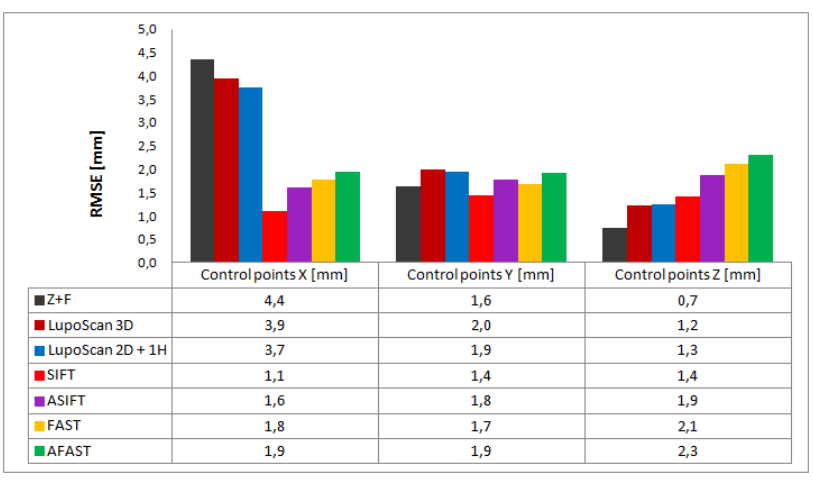

Figure 4. The quality assessment of relative orientation RSME on marked control points

The results (Figure 4) indicated that the proposed novel method for X coordinate of control point achieved higher accuracy for SIFT, ASIFT, FAST and AFAST with RMSE $1.1 \mathrm{~mm}, 1.6 \mathrm{~mm}$, $1.8 \mathrm{~mm}$ and $1.9 \mathrm{~mm}$, respectively in comparison to the existing methods $\mathrm{Z}+\mathrm{F}$, LupoScan 3D and, LupoScan 2D+1H with RMSE $4.4 \mathrm{~mm}, 3.9 \mathrm{~mm}$ and $3.7 \mathrm{~mm}$ respectively. The results for the $\mathrm{Y}$ coordinate of the control point achieved comparable results for all tested methods. The $\mathrm{Z}$ coordinate of control points demonstrated that the existing methods achieved slightly better RMSE values in comparison to the proposed method. Although these values remain acceptable, not exceeding $2.3 \mathrm{~mm}$. In addition, the proposed method demonstrates similar RMSE values for $\mathrm{X}, \mathrm{Y}$ and $\mathrm{Z}$ coordinates, ensuring that the developed transformation model (parameters) are correct, while the existing methods had a significant RMSE difference for $X$ coordinate compare to $\mathrm{Y}$ and $\mathrm{Z}$, which can have an effect on the quality of TLS point cloud registration.

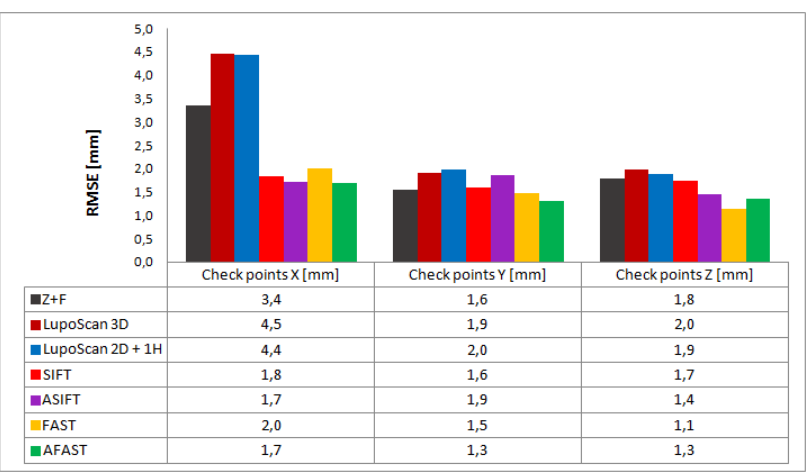

Figure 5. The quality assessment of relative orientation RSME on marked check points

To perform the independent analysis of TLS registration, the quality assessment on marked check points (which were not used to compute transformation parameters) was carried out, and the results are presented in figure 5 .

The results show (Figure 5) a similar trend for the $\mathrm{X}$ coordinate of the check point where the proposed method offers a lower RMSE value in comparison to existing methods, while the $\mathrm{Y}$ and $\mathrm{Z}$ coordinates of check points have achieved a similar RMSE value. Results in both figures 4 and 5 have a similar RMSE value, which can confirm that the TLS registration process was completed correctly.

\subsection{The reliability assessment - the robustness analysis}

On the completion of the first part of data analysis for relative registration and quality assessment with RMSE for control and check points. The next step is to carry out a reliability assessment of tie points (control points). Table 2 presents the results of statistical analysis (minimum, maximum, average, and median) for reliability factors based on their number of points.

\begin{tabular}{|c|c|c|c|c|c|}
\hline Method & Existing & \multicolumn{4}{|c|}{ Features Based Detection } \\
\cline { 3 - 6 } & $\begin{array}{c}\text { Z+F, } \\
\text { LupoScan })\end{array}$ & SIFT & ASIFT & FAST & AFAST \\
\hline \multicolumn{7}{|c|}{ Internal reliability factors } \\
\hline Min & 0.01 & 0.95 & 0.99 & 0.52 & 0.98 \\
\hline Max & 0.82 & 1.00 & 1.00 & 1.00 & 1.00 \\
\hline Average & 0.57 & 0.99 & 1.00 & 0.98 & 0.99 \\
\hline Median & 0.65 & 0.99 & 1.00 & 0.99 & 1.00 \\
\hline \multicolumn{7}{|c|}{ Number of points } \\
\hline Min & \multirow{6}{*}{6} & 345 & 3029 & 57 & 999 \\
\cline { 4 - 6 } & 489 & 4770 & 741 & 5346 \\
\cline { 4 - 6 } Max & 440 & 3852 & 302 & 2638 \\
\cline { 3 - 6 } Average & 485 & 3756 & 108 & 1569 \\
\hline Median &
\end{tabular}

Table 2. The robustness analysis of reliability factors.

As reported in the literature (Prószyński, 1994), the reliability factor must be higher than 0.5 for all points used in the registration process to guarantee the robustness of the TLS point cloud registration. If the reliability factor is below 0.5 , then the developed TLS registration could have an uncontrolled point by other points taking part in the bundle adjustment process, which means that it cannot be assessed if it is a deviation value or an outlier. The results presented in Table 2 indicates that one of the values ( $\mathrm{min}$ ) for the existing method is below the required 0.5 and should be eliminated for further data processing. On the other hand, the proposed method achieved very high-reliability factor values for all detectors, confirming the robustness of the method. The TLS registration requires a minimum of 4 control points (Van Genchten, 2008) for point cloud registration. In this research, 6 control points were used for the target-based method. However, the reliability factor for Min remains low. The proposed method uses a detector, which detects a high number of point and improves their robustness to eliminate the outliners.

Table 3 presents the results of RMSE for relative registration before and after point elimination for control and check points based on the threshold of reliability factor and RMSE on eliminated point. This approach has been used to improve the robustness of the TLS registration process by eliminating uncontrolled points. The results show the significant improvement of RMSE on the X coordinate for all target-based methods, while there is a similar result for $\mathrm{Y}$ and $\mathrm{Z}$ coordinates. The RMSE value for the eliminated point on $X$ coordinate was $>10 \mathrm{~mm}$ and difficult for detection-based deviation analysis only. Results after point elimination are similar for control and check points, which can confirm that the TLS registration process was completed correctly. 


\begin{tabular}{|c|c|c|c|c|c|c|c|c|c|c|}
\hline \multirow{2}{*}{ Method } & \multirow{2}{*}{ Filtration } & \multicolumn{3}{|c|}{ RMSE on control points } & \multicolumn{3}{|c|}{ RMSE on check points } & \multicolumn{3}{|c|}{ RMSE on eliminated point } \\
\hline & & $\mathrm{X}[\mathrm{mm}]$ & $\mathrm{Y}[\mathrm{mm}]$ & $\mathrm{Z}[\mathrm{mm}]$ & $\mathrm{X}[\mathrm{mm}]$ & $\mathrm{Y}[\mathrm{mm}]$ & $\mathrm{Z}[\mathrm{mm}]$ & $\mathrm{X}[\mathrm{mm}]$ & $\mathrm{Y}[\mathrm{mm}]$ & $\mathrm{Z}[\mathrm{mm}]$ \\
\hline \multirow{2}{*}{$\mathrm{Z}+\mathrm{F}$} & Before & 4.4 & 1.6 & 0.7 & 3.4 & 1.6 & 0.4 & \multirow{2}{*}{10.1} & \multirow{2}{*}{2.3} & \multirow{2}{*}{1.7} \\
\hline & After & 0.7 & 1.3 & 0.8 & 1.4 & 1.1 & 0.6 & & & \\
\hline \multirow{2}{*}{ LupoScan 3D } & Before & 3.9 & 2.0 & 1.2 & 4.5 & 1.9 & 2.0 & \multirow{2}{*}{12.2} & \multirow{2}{*}{3.1} & \multirow{2}{*}{6.1} \\
\hline & After & 1.3 & 1.1 & 0.9 & 2.7 & 2.4 & 3.2 & & & \\
\hline \multirow{2}{*}{ LupoScan $2 \mathrm{D}+1 \mathrm{H}$} & Before & 3.0 & 2.0 & 1.4 & 3.3 & 1.4 & 0.7 & \multirow{2}{*}{12.4} & \multirow{2}{*}{3.1} & \multirow{2}{*}{2.1} \\
\hline & After & 1.2 & 1.9 & 1.3 & 2.4 & 2.6 & 1.9 & & & \\
\hline
\end{tabular}

Table 3. Results of the relative registration process in $\mathrm{Z}+\mathrm{F}$ and LupoScan software with point filtration based on reliability matrix analysis

The results show the significant improvement of RMSE on the $\mathrm{X}$ coordinate for all target-based methods, while there is a similar result for $\mathrm{Y}$ and $\mathrm{Z}$ coordinates. The RMSE value for the eliminated point on $\mathrm{X}$ coordinate was $>10 \mathrm{~mm}$ and difficult for detection-based deviation analysis only. Results after point elimination are similar for control and check points, which can confirm that the TLS registration process was completed correctly.

\subsection{Exterior registration - quality assessment}

Figure 6 presents the results of the exterior registration using "free" adjustment on the control points using Z+F, LupoScan 3D, LupoScan 2D+1H (existing methods), SIFT, ASIFT, FAST and AFAST (novel proposed methods).

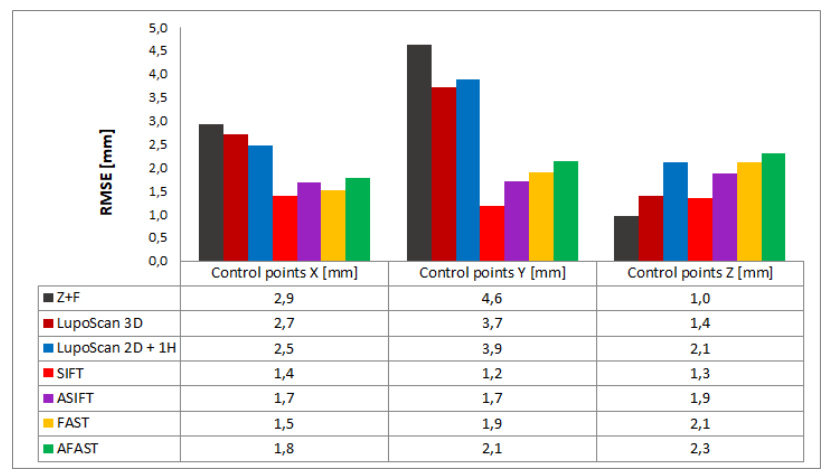

Figure 6. The quality assessment of exterior orientation RSME on marked control points

The results (Figure 6) indicated that the proposed novel method for $\mathrm{X}$ and $\mathrm{Y}$ coordinate of control point achieved higher accuracy for SIFT, ASIFT, FAST and AFAST with RMSE below $2.1 \mathrm{~mm}$ in comparison to the existing methods $\mathrm{Z}+\mathrm{F}$, LupoScan 3D and, LupoScan 2D+1H with RMSE for all values being above $2.5 \mathrm{~mm}$. The $\mathrm{Z}$ coordinate of control points demonstrated that the existing methods achieved slightly better RMSE values in comparison to the proposed method. Although these values remain acceptable, not exceeding $2.3 \mathrm{~mm}$. In addition, the proposed method demonstrates similar RMSE values for $\mathrm{X}, \mathrm{Y}$ and $\mathrm{Z}$ coordinates, ensuring that the developed transformation model (parameters) are correct, while the existing methods had a significant RMSE difference for $\mathrm{Y}$ coordinate compare to $\mathrm{X}$ and $\mathrm{Z}$, which can have an effect on quality of TLS point cloud exterior registration.

The results of the quality assessment on marked check points (which were not used to compute transformation parameters) are presented in figure 7.

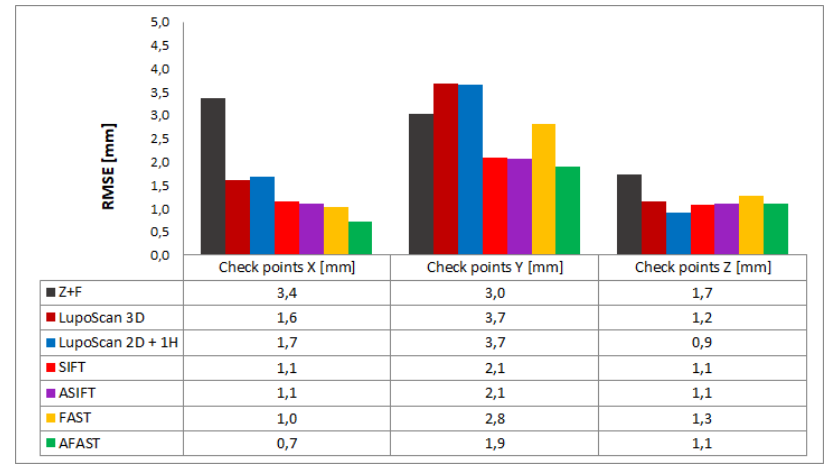

Figure 7. The quality assessment of exterior orientation RSME on marked check points

The results (Figure 7) show a similar trend for $\mathrm{X}$ and $\mathrm{Y}$ coordinates of check point where the proposed method offers a lower RMSE value in comparison to existing methods, while the $\mathrm{Z}$ coordinate of check points are similar for RMSE value. Results in both figures bb and cc have a similar RMSE value, which can confirm that the TLS exterior registration process was completed correctly.

\section{CONCLUSIONS}

An important element during an inventory of historical objects is the correct determination of the ground control points uses for TLS point cloud registration in the external reference system. Often, due to external factors (such as the impossibility to mark points or place on the object, complex shape of the object, narrow spaces, i.e.), it is difficult to set points in terms of geometry correctly. Due to that fact, it is necessary to determine the procedure of observation, filtration and validation in the bundle adjustment process based on the extended reliability factors analysis. The results in Table 3 show that differences between RMS on control and check points significantly exceeded the values of measurement errors. Based on the assessment of the feature-based methods, due to a large number of tie point, the RMSE values on control and check points are similar because of their number and distribution. In that case, the reliability factor analysis shows that the detected point allows performing robust relative TLS registration.

\section{ACKNOWLEDGEMENTS}

The research was funded by the Warsaw University of Technology within the Excellence Initiative: Research University (IDUB) programme (No. 1820/55/Z01/2021). 


\section{REFERENCES}

Abbate, E., Sammartano, G., Spanò, A., 2019. Prospective upon multi-source urban scale data for 3D documentation and monitoring of urban legacies. ISPRS - Int. Arch. Photogramm. Remote Sens. Spat. Inf. Sci. XLII-2/W11, 11-19. https://doi.org/10.5194/isprs-archives-XLII-2-W11-11-2019.

Arif, R., Essa, K., 2017. Evolving techniques of documentation of a world heritage site in Lahore. ISPRS - Int. Arch. Photogramm. Remote Sens. Spat. Inf. Sci. XLII-2/W5, 33-40. https://doi.org/10.5194/isprs-archives-XLII-2-W5-33-2017.

Baarda, W., 1968. A testing procedure for use in geodetic network. Publications on Geodesy, New Series, Netherlands Geodetic Commission, Delft.

Cheng, L., Chen, S., Liu, X., Xu, H., Wu, Y., Li, M., Chen, Y., 2018. Registration of laser scanning point clouds: A review. Sensors (Switzerland) 18. https://doi.org/10.3390/s18051641.

Cipriani, L., Bertacchi, S., Bertacchi, G., 2019. An optimised workflow for the interactive experience with cultural heritage through reality-based 3D models: Cases study in archaeological and urban complexes. ISPRS - Int. Arch. Photogramm. Remote Sens. Spat. Inf. Sci. XLII-2/W11, 427-434. https://doi.org/10.5194/isprs-archives-XLII-2-W11-427-2019.

Deng, H., Birdal, T., Ilic, S., 2018. PPF-FoldNet: Unsupervised Learning of Rotation Invariant 3D Local Descriptors.

Dong, Z., Liang, F., Yang, B., Xu, Y., Zang, Y., Li, J., Wang, Y., Dai, W., Fan, H., Hyyppä, J., Stilla, U., 2020. Registration of large-scale terrestrial laser scanner point clouds: A review and benchmark. ISPRS J. Photogramm. Remote Sens. 163, 327-342. https://doi.org/10.1016/j.isprsjprs.2020.03.013.

Durrant-Whyte, H., Bailey, T., 2006. Simultaneous localisation and mapping: Part I. IEEE Robot. Autom. Mag. 13, 99-108. https://doi.org/10.1109/MRA.2006.1638022.

Grussenmeyer, P., Yasmine, J., 2004. Photogrammetry for the Preparation of Archaeological Excavation. A 3D Restitution According to Modern and Archive Images of Beaufort Castle landscape (Lebanon). Int. Arch. Photogramm. Remote Sens.

Hatzopoulos, J.N., Stefanakis, D., Georgopoulos, A., Tapinaki, S., Pantelis, V., Liritzis, I., 2017. Use of various surveying technologies to $3 \mathrm{D}$ digital mapping and modelling of cultural heritage structures for maintenance and restoration purposes: The Tholos in Delphi, Greece. Mediterr. Archaeol. Archaeom. 17, 311-336. https://doi.org/10.5281/zenodo.1048937.

Heras, V., Sinchi, E., Briones, J., Lupercio, L., 2019. Urban heritage monitoring, using image processing techniques and data collection with terrestrial laser scanner (TLS), case study cuenca-Ecuador. ISPRS Ann. Photogramm. Remote Sens. Spat. Inf. Sci. 42, 609-613. https://doi.org/10.5194/isprs-ArchivesXLII-2-W11-609-2019.

Kot, P., Markiewicz, J., Muradov, M., Lapinski, S., Shaw, A., Zawieska, D., Tobiasz, A., Al-Shamma'A, A., 2020. Combination of the photogrammetric and microwave remote sensing for Cultural Heritage documentation and preservation preliminary results. Int. Arch. Phot. Remote Sens. Spat. Inf. Sci. - ISPRS Arch. 43, 1409-1413. https://doi.org/10.5194/isprsarchives-XLIII-B2-2020-1409-2020.
Liu, Y., 2006. Automatic registration of overlapping 3D point clouds using closest points. Image Vis. Comput. 24, 762-781. https://doi.org/10.1016/j.imavis.2006.01.009.

Markiewicz, J., Łapiński, S., Kot, P., Tobiasz, A., Muradov, M., Nikel, J., Shaw, A., Al-Shamma'a, A., 2020. The quality assessment of different geolocalisation methods for a sensor system to monitor structural health of monumental objects. Sensors (Switzerland) 20, 1-39. https://doi.org/10.3390/s20102915.

Markiewicz, J., Zawieska, D., 2019. The Influence of the Cartographic Transformation of TLS Data on the Quality of the Automatic Registration. Appl. Sci. 9, 509. https://doi.org/10.3390/app9030509.

Markiewicz, J., Zawieska, D., Podlasiak, P., 2017. Comparing multi-source photogrammetric data during the examination of verticality in a Monumental tower. Int. Arch. Photogramm. Remote Sens. Spat. Inf. Sci. - ISPRS Arch. 42, 475-480. https://doi.org/10.5194/isprs-archives-XLII-2-W3-475-2017.

Nuchter, A., Lingemann, K., Hertzberg, J., 2007. 6D SLAM-3D Mapping Outdoor Environments. J. F. Robot. 24, 699-722. https://doi.org/10.1002/rob.20209.

Polish Monuments, 2021. Tin-Roofed Palace. URL http://www.polskiezabytki.pl/m/obiekt/7836/Warszawa__Palac_Pod_Blacha/ (accessed 4.24.21).

Polish Tourism Organisation, 2021. The Royal Castle in Warsaw. URL https://www.pot.gov.pl/pl/turystycznaszkola/plastyka-muzyka-sztuka/zamek-krolewski (accessed 4.24.21).

Prószyński, W., 1994. Criteria for internal reliability of linear least squares models. Bull. Géodésique 68, 162-167. https://doi.org/10.1007/BF00808289.

Remondino, F., El-Hakim, S., 2006. Image-based 3D Modelling: A Review. Photogramm. Rec. 21, 269-291. https://doi.org/10.1111/j.1477-9730.2006.00383.x.

Rofatto, V.F., Matsuoka, M.T., Klein, I., Veronez, M.R., Bonimani, M.L., Lehmann, R., 2020. A half-century of Baarda's concept of reliability: a review, new perspectives, and $\begin{array}{llll}\text { applications. Surv. } & \text { Rev. 52, 261-277. }\end{array}$ https://doi.org/10.1080/00396265.2018.1548118.

Sprickerhof, J., Nüchter, A., Lingemann, K., Hertzberg, J., 2009. An Explicit Loop Closing Technique for 6D SLAM. Computer (Long. Beach. Calif). 1-6.

Stylianidis, E., 2019. CIPA - Heritage Documentation: 50 Years: Looking Backwards. ISPRS - Int. Arch. Photogramm. Remote Sens. Spat. Inf. Sci. XLII-2/W14, 1-130. https://doi.org/10.5194/isprs-archives-XLII-2-W14-1-2019.

The Royal Castle in Warsaw, 2021. The Tin-Roofed Palace. URL https://www.zamek-krolewski.pl/en/the-tin-roofed-palace (accessed 4.24.21).

Theiler, P.W., Schindler, K., 2012. Automatic Registration of Terrestrial Laser Scanner Point Clouds Using Natural Planar Surfaces. ISPRS Ann. Photogramm. Remote Sens. Spat. Inf. Sci. I-3, 173-178. https://doi.org/10.5194/isprsannals-I-3-1732012. 
Tobiasz, Markiewicz, Łapiński, Nikel, Kot, Muradov, 2019. Review of Methods for Documentation, Management, and Sustainability of Cultural Heritage. Case Study: Museum of King Jan III's Palace at Wilanów. Sustainability 11, 7046. https://doi.org/10.3390/su11247046.

Van Genchten, B., 2008. Theory and practice on Terrestrial Laser Scanning. Learn. tools Adv. three-dimensional Surv. risk Aware. Proj. 1-241. https://doi.org/978-84-8363-312-0.

Van Genderen, J.L., 2011. Airborne and terrestrial laser scanning. Int. J. Digit. Earth 4, 183-184. https://doi.org/10.1080/17538947.2011.553487.

Vosselman, G., Maas, H.-G., 2010. Airborne and Terrestrial Laser Scanning. CRC Press, Boca Raton. 